\title{
Reduced expression of follicle stimulating hormone receptor mRNA and protein in pregnancies complicated by pre-eclampsia
}

\author{
MO LI ${ }^{1 *}$, YIFAN JIA $^{2 *}$, YAN LING $^{3}$, YILU CHEN $^{1}$, LU ZHANG $^{1}$, DAN LUO $^{1}$, LIDAN LAI $^{1}$, \\ MEIJUN GUO ${ }^{1}$, DALEI ZHANG ${ }^{1}$, MIN REN ${ }^{1}$, HONG XU $^{1}$ and HAIBIN KUANG ${ }^{1}$ \\ ${ }^{1}$ Jiangxi Provincial Key Laboratory of Reproductive Physiology and Pathology, Department of Physiology, \\ School of Medicine, Nanchang University, Nanchang, Jiangxi 330006; ${ }^{2}$ Department of Clinical Medicine, \\ School of Queen Mary, Nanchang University; ${ }^{3}$ Department of Obstetrics and Gynecology, \\ Jiangxi Province People's Hospital, Nanchang, Jiangxi 330006, P.R. China
}

Received April 13, 2016; Accepted March 16, 2017

DOI: $10.3892 / \mathrm{mmr} .2017 .6599$

\begin{abstract}
Expression and function of the follicle-stimulating hormone receptor (FSHR) are traditionally thought to be limited to the ovary in females. However, recent studies have indicated that the FSHR is also expressed in endothelial cells of the placental vasculature, and that the haploinsufficiency of the feto-placental FSHR impaired the growth of the mouse placenta. The aim of the current study was to investigate the placental expression of FSH and FSHR in pregnancies complicated by pre-eclampsia. Placental tissue samples were collected from 20 pregnancies with pre-eclampsia and 25 normal pregnancies. Placental FSH and FSHR mRNA levels were measured by reverse transcription-quantitative polymerase chain reaction (RT-qPCR), while FSH, FSHR and CD31 protein expression were examined by immunohistochemistry. Additionally, levels of serum FSH were measured by chemical luminescence immunity assay. The results demonstrated that no significant difference was observed in serum FSH levels and expression levels of placental FSH mRNA and protein between normal pregnancy and pre-eclampsia. However, RT-qPCR results indicated that the expression level of FSHR mRNA in pre-eclamptic placental samples was significantly lower than normal pregnancies. Immunostaining results from normal pregnant samples indicated that the FSHR protein was strongly expressed in the endothelial cells of blood vessels in the chorionic villi, moderately expressed in stromal cells of the villus, but not expressed in trophoblast cells of the term placenta. The staining intensity of FSHR-positive area was
\end{abstract}

Correspondence to: Dr Haibin Kuang or Dr Hong Xu, Jiangxi Provincial Key Laboratory of Reproductive Physiology and Pathology, Department of Physiology, School of Medicine, Nanchang University, 461 Bayi Road, Nanchang, Jiangxi 330006, P.R. China

E-mail: kuanghaibin@ncu.edu.cn

E-mail: cray0127@163.com

*Contributed equally

Key words: FSH receptor, FSH, pre-eclampsia, human placenta significantly lower in the placental villi of pre-eclampsia, when compared with the normal control group. In conclusion, expression levels of placental FSHR mRNA and protein are significantly reduced in pregnancies complicated with pre-eclampsia in the present study. Further studies may investigate whether FSHR could be used as a biomarker for the prediction of pre-eclampsia.

\section{Introduction}

Pre-eclampsia is a pregnancy-specific syndrome characterized by hypertension and significant proteinuria developed at or after 20 weeks of pregnancy in a previously normotensive, non-proteinuric patient $(1,2)$. It affects $\sim 5-10 \%$ of all pregnancies worldwide and is a major cause of maternal and perinatal morbidity and mortality in developed countries $(1,3)$. Although the etiology of pre-eclampsia is still not fully clear, strong evidence supports the involvement of inadequate trophoblast invasion, failed remodeling of the spiral arteries, imbalance of angiogenic and antiangiogenic factors and endothelial cell dysfunction (1-5). Consequently, elucidating disorder factors of placental angiogenesis is crucial in understanding the pathophysiological process of pre-eclampsia.

Follicle stimulating hormone (FSH), an anterior pituitary gonadotroph-derived heterodimeric glycoprotein which binds G protein-coupled FSH receptor (FSHR), is promoted by hypothalamic decapeptide gonadotrophin-releasing hormone and serves a critical role in hypothalamic-pituitary-gonadal axis $(6,7)$. Traditional considerations manifest the physiological structure and function of the FSH/FSHR system within gonads that stimulates growth of follicles and synthesis of estrogens in the ovary or promotes spermatogenesis in the testes $(6,8)$. However, previous reports revealed that the FSH/FSHR system serves an important role in extragonadal tissues and organs, including prostanoid synthesis of bovine cervix $(8,9)$, electrical activity of the mouse myometrium $(10,11)$, and some organs unrelated to reproduction (12). For instance, FSHR expression of osteoclast is related to bone resorption, which aggravates periodontitis-related alveolar bone loss without estrogen deficiency (12-14). Its relevance to angiogenesis has been also reported well in previous research $(15,16)$. Studies 
indicated that the FSHR was expressed in the endothelial cells of human placental chorionic villi and umbilical vein at term (15). Stilley et al $(8,15)$ revealed that FSH promoted the formation of endothelial tubes and other angiogenic processes without increasing secretion of vascular endothelial growth factor (VEGF). Furthermore, the study indicated that the haplo-insufficiency of the feto-placental FSHR impaired the growth of the mouse placenta (8). In addition, Radu et al (17) determined that the FSHR was selectively expressed on the endothelium of blood vessels in a wide range of tumors, and endothelial FSHR expression in breast cancer was associated with vascular remodeling at tumor peripheries (18). In light of the evidence pointing to roles of FSHR in the angiogenesis, the authors hypothesized that abnormal expression of the FSH/FSHR system would present in the placentas of women with pre-eclampsia.

To verify the hypothesis, the authors examined placental mRNA and protein expression and localization of FSH and FSHR by RT-qPCR and immunohistochemistry methods in normotensive control and pre-eclamptic women. Additionally, serum levels of maternal FSH were also tested using chemiluminescence immunoassay. The results indicated that FSHR mRNA and protein levels were significantly decreased in the placentas of women with pre-eclampsia.

\section{Materials and methods}

Patients. The present study was approved by the Ethical Committee of Nanchang University (Nanchang, China) and Jiangxi Province People's Hospital (Nanchang, China), and informed consent was obtained from each participant. Placentas were collected from pregnancies with: (1) Normal pregnancy (maternal blood pressure $<140 / 90 \mathrm{mmHg}$, absence of proteinuria and no medical complications), (2) severe pre-eclampsia (new-onset hypertension, defined as systolic blood pressure of $>160 \mathrm{mmHg}$ or diastolic blood pressure of $>110 \mathrm{mmHg}$, with at least two measurements, accompanying by significant proteinuria $>5 \mathrm{~g} / 24 \mathrm{~h}$ or $3+$ by dipstick in two random samples collected at $>4 \mathrm{~h}$ interval after 20 weeks of gestation). Those who developed renal disease, gestational diabetes, spontaneous abortion, transient hypertension of pregnancy, intrauterine fetal death, fetal chromosomal abnormalities, congenital abnormalities, pregnancies conceived by fertility treatment, or had hereditary history and smoking and alcohol the history were not included in the study. The clinical characteristics of patients and controls are presented in Table I. Tissues were collected from the villous tree within $1 \mathrm{~h}$ following delivery. To minimize blood contamination, each piece of tissue was intensively washed in Dulbecco's phosphate-buffered saline (Gibco; Thermo Fisher Scientific, Inc., Waltham, MA, USA). Tissue samples were then snap-frozen and stored at $-80^{\circ} \mathrm{C}$.

$R N A$ isolation and RT-qPCR. Total RNA was extracted from placental tissues with the RNAiso Plus solution (Takara Biotechnology Co., Ltd., Dalian, China) according to the manufacturer's protocol. RNA $(2 \mu \mathrm{g})$ samples were reverse-transcribed into single-stranded cDNA in a $25 \mu \mathrm{l}$ reaction mixture, containing $4 \mu \mathrm{l} 5 \mathrm{X}$ reaction buffer, $1 \mu \mathrm{l}$ RNase inhibitor, $2 \mu 110 \mathrm{mM}$ dNTP, $1 \mu 1$ reverse transcriptase and $1 \mu 1$ $10 \mu \mathrm{M}$ primers (Takara Biotechnology Co., Ltd.). RT-qPCR was then performed in a $20 \mu \mathrm{l}$ reaction volume containing $10 \mu 12 X$ Brilliant SYBR Green Mix (Takara Biotechnology Co., Ltd.), $2 \mu \mathrm{l}$ template cDNA, $0.5 \mu \mathrm{M}$ primers, and $300 \mathrm{nM}$ reference dyes using the ABI thermal cycler 7500 (Applied Biosystems; Thermo Fisher Scientific, Inc.). The thermal cycling conditions were $95^{\circ} \mathrm{C}$ for $30 \mathrm{sec}$, followed by 40 cycles at $94^{\circ} \mathrm{C}$ for $5 \mathrm{sec}, 60^{\circ} \mathrm{C}$ for $34 \mathrm{sec}$. Melting curve analysis and agarose gel electrophoresis were conducted following the RT-qPCR assays to monitor PCR product purity. The results were analyzed using ABI Prism 7500 software (Applied Biosystems; Thermo Fisher Scientific, Inc.). 18S rRNA was used for normalization (19). The following primers were used: FSH sense, 5'-CCACTTGGTGTGCTGGCTACT-3', and antisense, 5'-GGCCTGGCTGGGTCCTTATA-3'; FSHR sense, 5'-GCCATGCTGCCAGTGTCAT-3', and antisense, 5'-GAG GGCAGCTGCAAAAGC-3'; 18S sense, 5'-GCTGAGAAG ACGGTCGAACT-3', and antisense, 5'-TTAATGATCCTT CCGCAGGT-3'.

Immunohistochemistry. Tissues were fixed in Bouin's solution, dehydrated, and embedded in paraffin. Tissue sections were deparaffinized, and rehydrated in a graded series of ethanol solutions. Endogenous peroxidase activity was blocked by incubating the sections in 3\% hydrogen peroxide in PBS for 10 min. Nonspecific binding was blocked with 5\% BSA in PBS for $30 \mathrm{~min}$. Then, the sections were incubated in rabbit anti-FSHR (1:200; ab113421; Abcam, Cambridge, UK), rabbit anti-CD31 (1:300; ZM-0044; ZSGB-Bio, Beijing, China) and mouse anti-FSH monoclonal antibody (1:150; ZA-0264; ZSGB-Bio) overnight at $4^{\circ} \mathrm{C}$. Following washing in PBS, the sections were incubated with a horseradish peroxidase-conjugated secondary antibody (1:200; ZM-0003; ZSGB-Bio) for $50 \mathrm{~min}$ at $37^{\circ} \mathrm{C}$. The primary antibody was visualized with fresh diaminobenzidine solution, together with counter-staining with Harris' hematoxylin. In some sections, the primary antibodies were omitted or replaced with rabbit or mouse pre-immune $\operatorname{IgG}$ as a negative control.

Analyses of immunohistochemical staining. Images were captured in three sections per sample using digital camera head DS-Fil (Nikon Corporation, Tokyo, Japan), and analyses of immunohistochemical staining were taken using NIS-ELEMENTF analysis system (Nikon Corporation). Under the same magnification (x100) and light intensity, each slide was measured in randomly selected eight fields. Mean values of optical density for positive cells were calculated using sections from normal pregnancy and severe pre-eclampsia.

Hormone measurements. Blood samples were collected into clotting tubes between 7:30 a.m. and 8:30 a.m. from the cubital vein during the routine visits at the end of gestation. Blood was centrifuged at $2,000 \mathrm{xg}$ for $20 \mathrm{~min}$ at $4^{\circ} \mathrm{C}$ and then stored at $-80^{\circ} \mathrm{C}$ until the assay. The serum concentration of FSH was measured using a chemiluminescence immunoassay kit (BD-2003; DPC Biermann GmbH, Bad Nauheim, Germany). The intra-and interassay coefficients of variation did not exceed $10 \%$. The cross-reactivities with other peptides and steroid hormones did not exceed $4 \%$. The detection limitation of the FSH kit is $0.2 \mathrm{mIU} / \mathrm{ml}$. 
Table I. Clinical characteristics of study population.

\begin{tabular}{|c|c|c|c|}
\hline Clinical characteristic & Normal pregnancy & Pre-eclampsia & P-value \\
\hline Case (n) & 25 & 20 & \\
\hline Maternal age (mean $\pm \mathrm{SD}$, years) & $27.3 \pm 4.2$ & $29.3 \pm 3.9$ & 0.37 \\
\hline Gestational age at delivery (mean $\pm \mathrm{SD}$, weeks) & $37.7 \pm 2.4$ & $34.7 \pm 2.6$ & 0.013 \\
\hline Birth weight (mean $\pm \mathrm{SD}, \mathrm{g})$ & $3347.6 \pm 311.6$ & $2806.5 \pm 665.3$ & $<0.001$ \\
\hline Maternal height (cm) & $163.1 \pm 7.8$ & $160.9 \pm 6.4$ & 0.314 \\
\hline Maternal weight (kg) & $60.2 \pm 4.5$ & $62.1 \pm 5.0$ & 0.175 \\
\hline Body mass index & $22.2 \pm 1.4$ & $23.0 \pm 2.1$ & 0.133 \\
\hline Systolic blood pressure (mean $\pm \mathrm{SD}, \mathrm{mmHg}$ ) & $106.3 \pm 11.3$ & $165.4 \pm 11.9$ & $<0.001$ \\
\hline Diastolic blood pressure (mean $\pm \mathrm{SD}, \mathrm{mmHg}$ ) & $69.3 \pm 10.2$ & $109.1 \pm 13.4$ & $<0.001$ \\
\hline Fetal sex (male/female) & $14 / 11$ & $9 / 11$ & $>0.05$ \\
\hline Serum FSH (mean $\pm \mathrm{SD}, \mathrm{mIU} / \mathrm{ml})$ & $2.92 \pm 0.95$ & $2.79 \pm 0.63$ & 0.61 \\
\hline
\end{tabular}

$\mathrm{SD}$, standard deviation; FSH, follicle stimulating hormone.
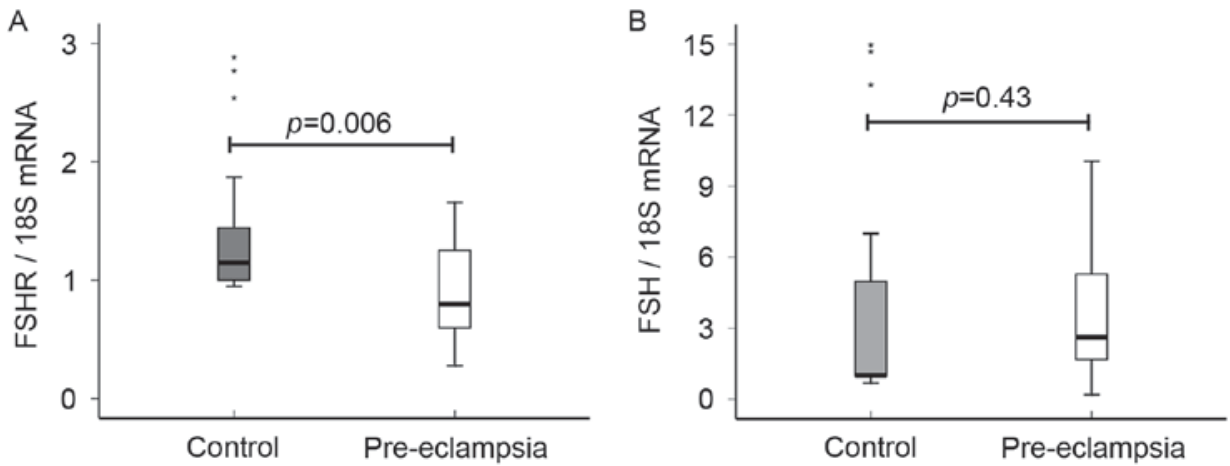

Figure 1. Expression levels of placental FSHR and FSH mRNA in normal controls and pregnancies with pre-eclampsia. (A) Box and whisker plots depicting relative expression levels of FSHR mRNA. (B) Box and whisker plots depicting relative expression levels of FSH mRNA. mRNAs levels were quantified using reverse transcription-quantitative polymerase chain reaction and normalized to $18 \mathrm{~S}$ rRNA. "denotes outliers. FSH, follicle-stimulating hormone; FSHR, follicle-stimulating hormone receptor.

Statistical analysis. Data were presented as means \pm standard deviation. Statistical analysis was performed by independentsamples t-test for parametric and Wilcoxon test for nonparametric data to determine the significance of the differences. Additionally, the chi-squared test was used to examine fetal sex. $\mathrm{P}<0.05$ was considered to indicate a statistically significant difference. All statistical analyses were performed using SPSS software (version, 13.0; SPSS, Inc., Chicago, IL, USA).

\section{Results}

Clinical data analysis. Compared with normal pregnancy, the gestational age of women with pre-eclampsia was 3 weeks shorter at delivery $(\mathrm{P}=0.013)$, and gained less weight during their pregnancies $(\mathrm{P}<0.001)$. However, there was no significant difference in serum concentrations of FSH between normal pregnancy and pre-eclampsia $(\mathrm{P}=0.61$; Table I).

FSHR expression in human placentas. RT-qPCR results indicated that expression level of placental FSHR mRNA in pre-eclamptic samples was significantly lower than that of the normal sample $(1.27 \pm 0.56,0.92 \pm 0.42 ; \mathrm{P}=0.006$; Fig. $1 \mathrm{~A})$. The authors then analyzed the spatiotemporal expression of the FSHR protein in the placental tissues by immunohistochemistry method (Fig. 2). Immunostaining results from normal pregnant samples demonstrated that the FSHR protein was strongly expressed in endothelial cells of blood vessels in the chorionic villi (confirmed by CD31 staining, Fig. 2A and B), moderately expressed in the chorionic stromal cells, but not expressed in trophoblast cells of term placenta (Fig. 2D and E). Compared to the normal control group, the staining intensity of the FSHR-positive area was significantly lower in the placental villi of pre-eclampsia $(\mathrm{P}=0.0018$; Fig. $3 \mathrm{~A})$, in accordance with the RT-qPCR results.

FSH expression in human placentas. RT-qPCR analysis revealed that no significant difference was observed in the expression levels of placental FSH mRNA between normal pregnancy and pre-eclampsia $(3.22 \pm 2.93,3.88 \pm 2.95 ; \mathrm{P}=0.43$; Fig. 1B). Furthermore, immunohistochemical analysis also verified the above results. Immunostaining results indicated that expression level of the FSH protein was generally low in the cytotrophoblasts and syncytiotrophoblasts, blood vessel and stroma of placental villi (Fig. 4A-F). Compared 


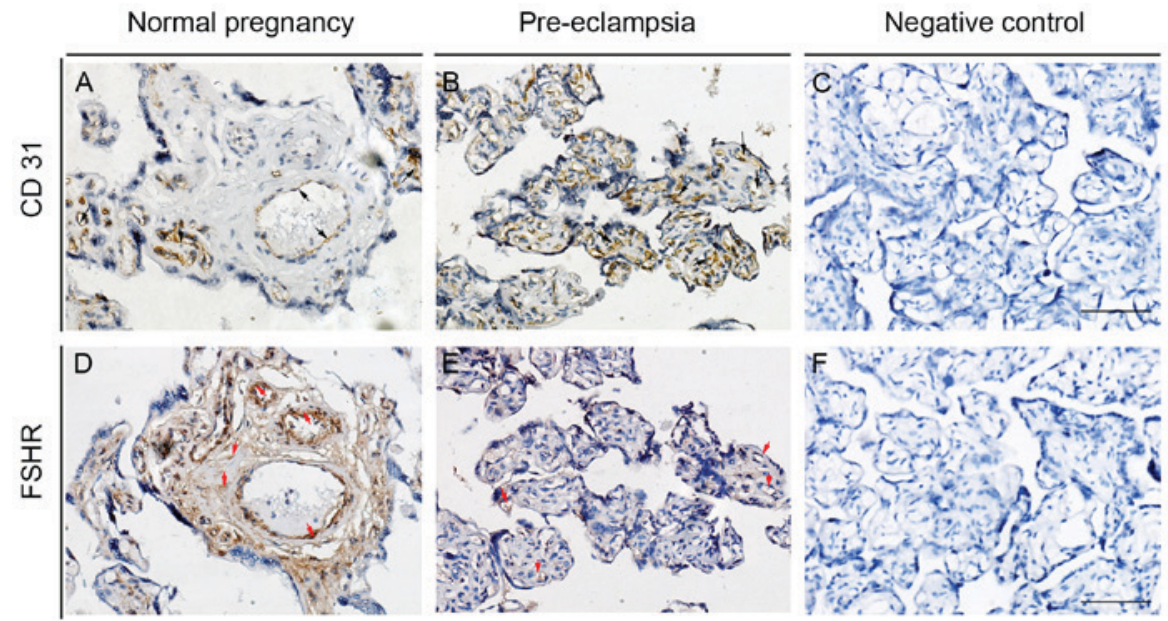

Figure 2. Expression of the FSHR protein in normal controls and pregnancies with pre-eclampsia. Serial sections of human placental tissues from (A and D) normal controls and (B and E) pre-eclampsia were stained with (A and B) CD31, (D and E) FSHR antibodies or (C and F) without primary antibodies. CD31 staining was confirmed endothelial cells identity of placental blood vessels. Arrows indicate positive cells (brownish yellow) of CD31 (black arrow) or FSHR (red arrow) staining. Scale bar, $50 \mu \mathrm{m}$. FSHR, follicle-stimulating hormone receptor.
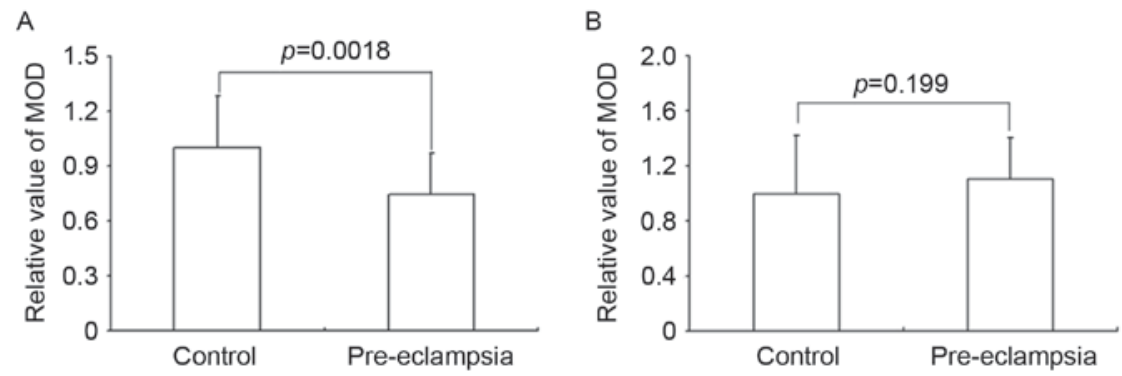

Figure 3. Relative optical density values of FSHR and FSH protein in the placental villi of normal controls and pregnancies with pre-eclampsia. (A) MOD of FSHR protein. (B) MOD of FSH protein. The results are normalized to control group and represented as the mean \pm standard deviation. FSHR, follicle-stimulating hormone receptor; FSH, follicle-stimulating hormone; MOD, mean values of optical density.

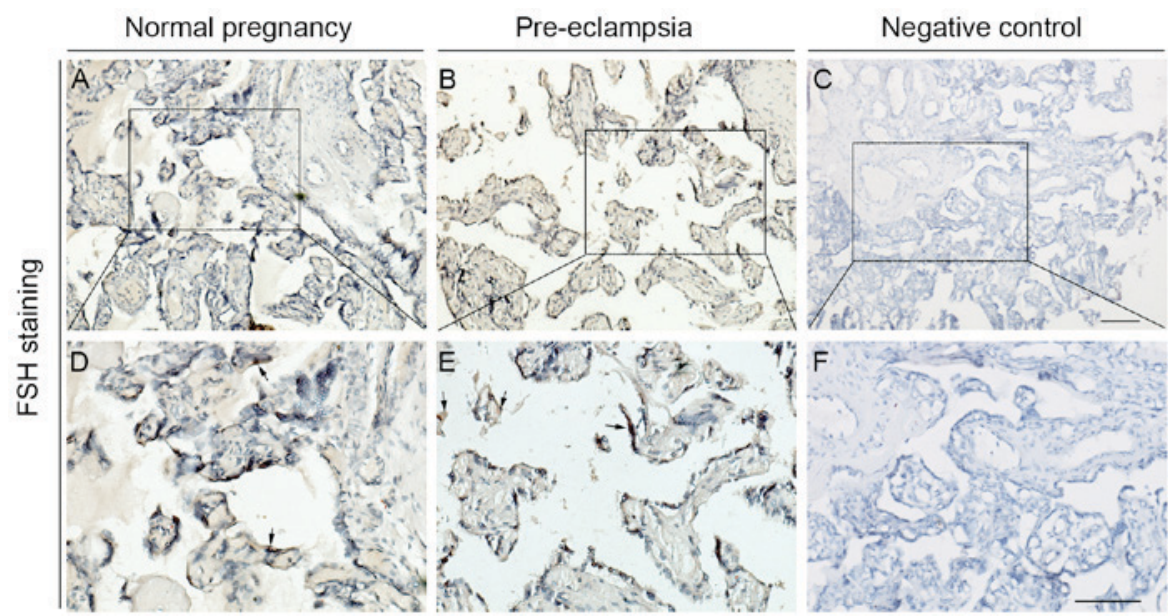

Figure 4. Expression of FSH protein in normal controls and pregnancies with pre-eclampsia. (A and D) Immunohistochemical staining of FSH in normal control placentas. (B and E) Immunohistochemical staining of FSH in pre-eclamptic placentas. (C and F) Negative control, the primary antibody was omitted or replaced by normal rabbit serum. Squared areas in A-C (magnification, $\mathrm{x} 100$ ) were magnified in the bottom with higher magnification (magnification, $\mathrm{x} 200$ ), respectively. Arrows indicate positive cells of FSH staining (brownish yellow). Scale bar, $50 \mu \mathrm{m}$. FSH, follicle-stimulating hormone.

to the normal control group, the staining intensity of the FSH-positive area was a little stronger in the placental villi of pre-eclampsia, but no significant difference was identified ( $\mathrm{P}=0.199$; Fig. 3B).

\section{Discussion}

The hypothesis that was investigated in the present study involved whether placental dysfunction associated with 
pre-eclampsia correlates with altered FSH and FSHR mRNA and protein expressions. The current results indicated that decreased FSHR mRNA and protein levels in placental tissues derived from pre-eclamptic women compared to those with uncomplicated pregnancies. No significant difference was demonstrated in serum FSH levels and expression levels of placental FSH mRNA and protein between normal pregnancy and pre-eclampsia.

In women, FSH serves an important role during the growth and development of ovarian follicles, including granulosa cell function and production of estrogens from androgen substrates $(6,7)$. It is generally believed that level of pituitary FSH in the peripheral blood is suppressed during pregnancy (20). Faiman et al (20) observed only low levels of radio-immunoassayable serum $\mathrm{FSH}$ throughout human pregnancy, and its concentrations averaged $0.39 \mathrm{mIU} / \mathrm{ml}$. The results identified that the level of serum FSH averaged $2.92 \mathrm{mIU} / \mathrm{ml}$ during the third trimester, which is consistent with Penny, Olambiwonnu and Frasier's results $(21,22)$. However, Jaffe, Lee and Midgley (23) indicated that $76 \%$ of 45 pregnant subjects displayed values $>6 \mathrm{mIU} / \mathrm{ml}$ and only $4 \%$ of subject's values $<3 \mathrm{mIU} / \mathrm{ml}(22,23)$. The difference between these results may have attributed to the different sampling times and numbers, assay methods and FSH antibody used in these studies. In addition, the current data indicated that no significant differences were identified in levels of serum FSH between normal pregnancies and pre-eclampsia, suggesting that locally produced FSH at the maternal-fetal interface may exert its physiological effects through paracrine ways. Stilley et al (8) revealed that both FSHB mRNA (encoding the FSH $\beta$ subunit) and CGA mRNA (encoding the common FSH $\alpha$ subunit) are present in the placental tissue, uterine deciduas and myometrium (24-26). The present RT-qPCR and immunostaining results also indicated that FSH was expressed in term placental tissues, but no significant difference was observed in the expression levels of placental FSH mRNA and protein between normal pregnancy and pre-eclampsia.

Previous studies have indicated that the FSHR is expressed in endothelial cells of placental blood vessels and FSH could promote angiogenesis of human umbilical vein endothelial cells through the FSHR $(8,15,27)$. The results indicated that expression levels of placental FSHR were significantly reduced in pregnancies complicated by pre-eclampsia. It suggests that decreased FSHR expression could contribute to aberrant angiogenesis and trophoblast development associated with pre-eclampsia. FSH stimulates angiogenesis possibly via a different mechanism (26). Fatima et al (28) demonstrated that FSH could upregulate mRNA and proteins of VEGF, fibroblast growth factors 2, and their receptors in vitro and in vivo in luteal cells of buffaloes. High/mid-dose FSH significantly stimulated VEGF secretion in the slow-growing follicles at $5 \% \mathrm{O}_{2}$ environments (16). However, recombinant human $\mathrm{FSH}$ directly stimulates angiogenesis without VEGF secretion in FSHR-expressing endothelial cells by the PI3 K/AKT signaling pathway (15). In addition, the FSHR is selectively expressed on the surface of the blood vessels of a wide range of tumors $(17,18,29-31)$. FSHR expression of endothelial cells may be involved in the proliferation of tumor tissues in this particular location, and could promote angiogenesis by inducing VEGF and VEGF receptor 2 signaling in tumor endothelial cells $(17,30)$.
Interestingly, relatively recent genetic studies identified an association of single nucleotide polymorphisms in the FSHR gene to preterm birth, polycystic ovary syndrome and premature ovarian failure (32-35). However, no significant association was identified in the comparison of genotypes and allele of the FSHR gene, rs1394205, with pre-eclampsia in a Chinese population with a small sample size $(\sim 100)$ reported $(32)$. To confirm the association of FSHR gene polymorphisms with pre-eclampsia, further genetic studies in other populations with larger sample sizes and denser markers are required for further investigation.

It should be noted that the present study has potential limitations. Firstly, the number of patients studied was relatively small, so further studies employing large numbers of samples are required to confirm the findings. Secondly, the authors did not completely assess all of the factors related to placental angiogenesis. Some known confounding factors, such as soluble Fms-like tyrosine kinase-1, soluble endoglin and VEGF were not included $(36,37)$. Finally, the design of the present study does not allow us to define if altered levels of placental FSHR mRNA and protein represent a response to abnormal placentation or its cause. Also, these events may be a component of an adaptation to placental hypoxia that incorporates other angiogenic factors as well.

Overall, the current findings indicated that the expression levels of placental FSHR mRNA and protein were significantly decreased in pregnancies complicated by pre-eclampsia. These results indicated that decreased FSHR expression could contribute to aberrant angiogenesis and trophoblast development associated with pre-eclampsia. In order to determine whether similar differences antedate the clinical onset of the disease, future longitudinal studies are needed to trace the mRNA and protein expression of FSHR in first and second trimester placenta and determine whether the results are the cause or effect.

\section{Acknowledgments}

The present study work was supported by the National Natural Science Foundation of China (grant nos. 81671486, 81270668, 30960118 and 81460226) and the 555 Project of Jiangxi Province Gan Po Excellence and Jiangxi Province and Nanchang University Postgraduate Innovation Project (grant nos. cx2015176 and cx2016355). The authors are grateful to all mothers who donated their placentas for the current study.

\section{References}

1. Young BC, Levine RJ and Karumanchi SA: Pathogenesis of preeclampsia. Annu Rev Pathol 5: 173-192, 2010.

2. Ji L, Brkić J, Liu M, Fu G, Peng C and Wang YL: Placental trophoblast cell differentiation: Physiological regulation and pathological relevance to preeclampsia. Mol Aspects Med 34: 981-1023, 2013

3. Escudero C, Celis C, Saez T, San Martin S, Valenzuela FJ, Aguayo C, Bertoglia P, Roberts JM and Acurio J: Increased placental angiogenesis in late and early onset pre-eclampsia is associated with differential activation of vascular endothelial growth factor receptor 2. Placenta 35: 207-215, 2014

4. Armant DR, Fritz R, Kilburn BA, Kim YM, Nien JK, Maihle NJ Romero R and Leach RE: Reduced expression of the epidermal growth factor signaling system in preeclampsia. Placenta 36: 270-278, 2015. 
5. Kappou D, Sifakis S, Androutsopoulos V, Konstantinidou A, Spandidos DA and Papantoniou N: Placental mRNA expression of angiopoietins (Ang)-1, Ang-2 and their receptor Tie-2 is altered in pregnancies complicated by preeclampsia. Placenta 35 : 718-723, 2014

6. Jiang X, Liu H, Chen X, Chen PH, Fischer D, Sriraman V, Yu HN, Arkinstall S and He X: Structure of follicle-stimulating hormone in complex with the entire ectodomain of its receptor. Proc Nat Acad Sci USA 109: 12491-12496, 2012.

7. Bernard DJ, Fortin J, Wang Y and Lamba P: Mechanisms of FSH synthesis: What we know, what we don't, and why you should care. Fertil Steril 93: 2465-2485, 2010.

8. Stilley JA, Christensen DE, Dahlem KB, Guan R, Santillan DA, England SK, Al-Hendy A, Kirby PA and Segaloff DL: FSH receptor (FSHR) expression in human extragonadal reproductive tissues and the developing placenta, and the impact of its deletion on pregnancy in mice. Biol Reprod 91: 74, 2014.

9. Mizrachi D and Shemesh M: Follicle-stimulating hormone receptor and its messenger ribonucleic acid are present in the bovine cervix and can regulate cervical prostanoid synthesis. Biol Reprod 61: 776-784, 1999.

10. Celik O, Tagluk ME, Hascalik S, Elter K, Celik N and Aydin NE: Spectrotemporal changes in electrical activity of myometrium due to recombinant follicle-stimulating hormone preparations follitropin alfa and beta. Fertil Steril 90 (Suppl 4): S1348-S1356, 2008.

11. Hascalik S, Celik O, Tagluk ME, Yildirim A and Aydin NE: Effects of highly purified urinary FSH and human menopausal FSH on uterine myoelectrical dynamics. Mol Hum Reprod 16 : 200-206, 2010.

12. Sun L, Peng Y, Sharrow AC, Iqbal J, Zhang Z, Papachristou DJ, Zaidi S, Zhu LL, Yaroslavskiy BB, Zhou H, et al: FSH directly regulates bone mass. Cell 125: 247-260, 2006.

13. Zhu LL, Blair H, Cao J, Yuen T, Latif R, Guo L, Tourkova IL, Li J, Davies TF, Sun L, et al: Blocking antibody to the $\beta$-subunit of FSH prevents bone loss by inhibiting bone resorption and stimulating bone synthesis. Proc Natl Acad Sci USA 109: 14574-14579, 2012.

14. Liu S, Cheng Y, Fan M, Chen D and Bian Z: FSH aggravates periodontitis-related bone loss in ovariectomized rats. J Dent Res 89: 366-371, 2010.

15. Stilley JA, Guan R, Duffy DM and Segaloff DL: Signaling through FSH receptors on human umbilical vein endothelial cells promotes angiogenesis. J Clin Endocrinol Metab 99: E813-E820, 2014.

16. Fisher TE, Molskness TA, Villeda A, Zelinski MB, Stouffer RL and Xu J: Vascular endothelial growth factor and angiopoietin production by primate follicles during culture is a function of growth rate, gonadotrophin exposure and oxygen milieu. Hum Reprod 28: 3263-3270, 2013.

17. Radu A, Pichon C, Camparo P, Antoine M, Allory Y, Couvelard A, Fromont G, Hai MT and Ghinea N: Expression of follicle-stimulating hormone receptor in tumor blood vessels. $\mathrm{N}$ Engl J Med 363: 1621-1630, 2010.

18. Planeix F, Siraj MA, Bidard FC, Robin B, Pichon C, Sastre-Garau X, Antoine M and Ghinea N: Endothelial follicle-stimulating hormone receptor expression in invasive breast cancer and vascular remodeling at tumor periphery. J Exp Clin Cancer Res 34: 12, 2015.

19. Livak KJ and Schmittgen TD: Analysis of relative gene expression data using real-time quantitative PCR and the 2(-Delta Delta C(T)) Method. Methods 25: 402-408, 2001.

20. Faiman C, Ryan RJ, Zwirek SJ and Rubin ME: Serum FSH and HCG during human pregnancy and puerperium. J Clin Endocrinol Metab 28: 1323-1329, 1968 .

21. Penny R, Olambiwonnu NO and Frasier SD: Follicle stimulating hormone (FSH) and luteinizing hormone-human chorionic gonadotropin ( $\mathrm{LH}-\mathrm{HCG}$ ) concentrations in paired maternal and cord sera. Pediatrics 53: 41-47, 1974.
22. Parlow AF, Daane TA and Dignam WJ: On the concentration of radioimmunoassayable FSH circulating in blood throughout human pregnancy. J Clin Endocrinol Metab 31: 213-214, 1970.

23. Jaffe RB, Lee PA and Midgley AR Jr: Serum gonadotropins before, at the inception of, and following human pregnancy. J Clin Endocrinol Metab 29: 1281-1283, 1969.

24. Winn VD, Haimov-Kochman R, Paquet AC, Yang YJ, Madhusudhan MS, Gormley M, Feng KT, Bernlohr DA, McDonagh S, Pereira L, et al: Gene expression profiling of the human maternal-fetal interface reveals dramatic changes between midgestation and term. Endocrinology 148: 1059-1079, 2007.

25. Dezso Z, Nikolsky Y, Sviridov E, Shi W, Serebriyskaya T, Dosymbekov D, Bugrim A, Rakhmatulin E, Brennan RJ, Guryanov A, et al: A comprehensive functional analysis of tissue specificity of human gene expression. BMC Biol 6: 49, 2008.

26. Eyster KM, Klinkova O, Kennedy V and Hansen KA: Whole genome deoxyribonucleic acid microarray analysis of gene expression in ectopic versus eutopic endometriusm. Fertil Steril 88: 1505-1533, 2007.

27. Reisinger K, Baal N, McKinnon T, Münstedt K and Zygmunt M: The gonadotropins: Tissue-specific angiogenic factors? Mol Cell Endocrinol 269: 65-80, 2007

28. Fatima LA, Evangelista MC, Silva RS, Cardoso AP, Baruselli PS and Papa PC: FSH up-regulates angiogenic factors in luteal cells of buffaloes. Domest Anim Endocrinol 45: 224-237, 2013.

29. Siraj MA, Pichon C, Radu A and Ghinea N: Endothelial follicle stimulating hormone receptor in primary kidney cancer correlates with subsequent response to sunitinib. J Cell Mol Med 16: 2010-2016, 2012 .

30. Siraj A, Desestret V, Antoine M, Fromont G, Huerre M, Sanson M, Camparo P, Pichon C, Planeix F, Gonin J, et al: Expression of follicle-stimulating hormone receptor by the vascular endothelium in tumor metastases. BMC Cancer 13: 246, 2013.

31. Renner M, Goeppert B, Siraj MA, Radu A, Penzel R Wardelmann E, Lehner B, Ulrich A, Stenzinger A, Warth A, et al: Follicle-stimulating hormone receptor expression in soft tissue sarcomas. Histopathology 63: 29-35, 2013.

32. Chen Y, Tong XH, Sun CJ and Zhang WY: Study of follicle-stimulating hormone receptor and tyrosine hydroxylase polymorphisms and pre-eclampsia in Chinese Han population. Zhonghua Yi Xue Za Zhi 90: 1213-1215, 2010 (In Chinese).

33. Katari S, Wood-Trageser MA, Jiang H, Kalynchuk E, Muzumdar R, Yatsenko SA and Rajkovic A: Novel inactivating mutation of the FSH receptor in two siblings of Indian origin with premature ovarian failure. J Clin Endocrinol Metab 100: 2154-2157, 2015.

34. Wu XQ, Xu SM, Liu JF, Bi XY, Wu YX and Liu J: Association between FSHR polymorphisms and polycystic ovary syndrome among Chinese women in north China. J Assist Reprod Genet 31: 371-377, 2014.

35. Ma L, Chen Y, Mei S, Liu C, Ma X, Li Y, Jiang Y, Ha L and $\mathrm{Xu} \mathrm{X}$ : Single nucleotide polymorphisms in premature ovarian failure-associated genes in a Chinese Hui population. Mol Med Rep 12: 2529-2538, 2015.

36. Brownfoot FC, Tong S, Hannan NJ, Hastie R, Cannon P, Tuohey L and Kaitu'u-Lino TJ: YC-1 reduces placental sFlt-1 and soluble endoglin production and decreases endothelial dysfunction: A possible therapeutic for preeclampsia. Mol Cell Endocrinol 413: 202-208, 2015

37. Wang J, Tao YM, Cheng XY, Zhu TF, Chen ZF, Yao H and Su LX: Vascular endothelial growth factor affects dendritic cell activity in hypertensive disorders of pregnancy. Mol Med Rep 12: 3781-3786, 2015. 